\title{
Using Microscopy Simulations in High School Teaching and Learning: Research from Low Income Schools and What it Means for Development
}

\section{Blasi*}

*Department of Educational Research, Technology, and Leadership (ERTL), The College of Education, The University of Central Florida, PO Box 161250, Orlando, FL 32816-1250; E-mail: lblasi@mail.ucf.edu

Once out-of-reach for typical science classrooms, the skills and knowledge accessible through advanced microscopy can be developed through simulations for students in low-income neighborhoods. NASA's Virtual Lab offers a suite of state-of-the-art simulated microscopes, including a Scanning Electron Microscope (SEM). Developed by the Beckman Institute, the Virtual Lab (Fig. 1 and 2) is available without charge online for educators, while providing an example for developers interested in designing, testing, and working to integrate simulations in microscopy into science classrooms. This paper discusses some of the lessons learned, drawing from a usability study $(\mathrm{N}=224)$ conducted in three high schools serving low-income areas. First the need for partnerships between developers and educators is described, then what was learned from the usability study in terms of (a) the artifact itself; (b) integration after the development in the lab; and (c) evaluation in this context, is presented to support future development.

The need for partnerships must be articulated within the larger need for education policy, strategic planning, and funding to support collaboration between the education community and developers. This commitment is needed in order to insure access, and then to harness the synergy to provide authentic lab experiences for all students that can be integrated into teaching and learning. (a) The usability study found that the artifact would have increased accessibility if (i) adjusted to accommodate the eye-hand coordination of a range of students; (ii) developed to include tools to augment use in the classroom, like a note-taking tool for students; (iii) expanded to explain the limits of the simulation compared to the actual tool; (iv) refined to include popups, roll-overs, and other guides to assist new users in classrooms. As with all NASA-developed products, 508 compliance under the Americans with Disabilities Act (ADA) also guides accessibility.

Beyond testing the artifact itself, the study documented (b) the promises and the barriers to integration after the development of the Virtual Lab. (i) Teachers need ways to easily integrate the tools in their current teaching, through lesson plans and assessment activities. (ii) The Virtual Lab presents a way to get scientific content to the classroom much more quickly than the textbook adoption cycle allows, but even with full support for integration, (iii) low levels of access to computers render the tool useless. A school where the science teacher has no access to the computer lab or to computers is as unable to use the Virtual Lab, as the science teacher who is in a school with little or no bandwidth to download the simulation and its specimens. From this partnership an approach to evaluation guided by educational goals was developed, articulating an evaluation process that moves from a larger vision to address four levels over time, with the evaluation team: (a) verifying the artifact; (b) checking the variation of the content; (c) verifying the use of the artifact in context; and (d) documenting the value in the field of education [1].

\section{References}

[1] L. Blasi and B. Alfonso, Increasing the transfer of simulation technology from R\&D into school settings. Simulation and Gaming: An International Journal of Theory, Practice, and Research. At press. (2006).

[2] The research was supported by The BellSouth Foundation, The UCF Teaching Fellows Academy, and a Summer Research Fellowship from the American Society for Engineering Education (ASEE). 


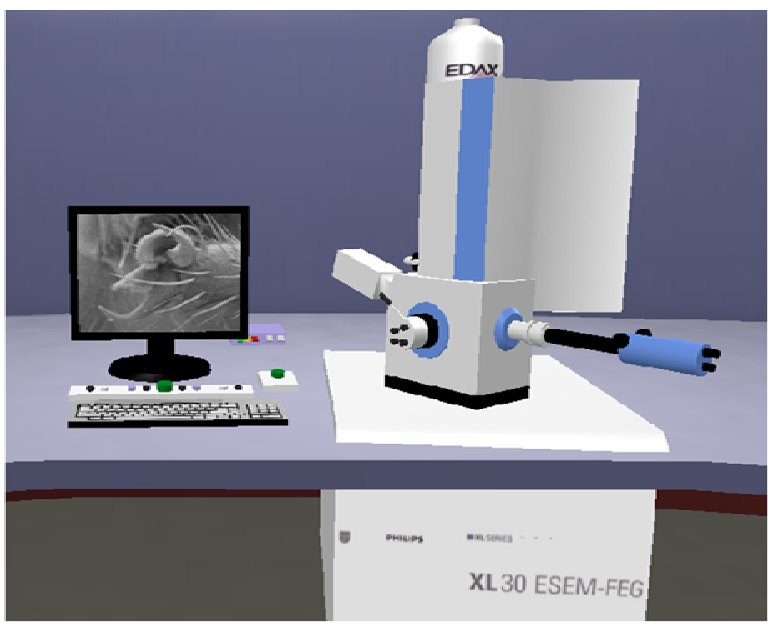

FIG. 1. An original graphic of NASA's Virtual Lab, a suite of simulations allowing users to access a range of microscopes. The overview of the project is online: http://learn.arc.nasa.gov/vlab/ with downloads and developer updates here: http://virtual.itg.uiuc.edu/index.shtml

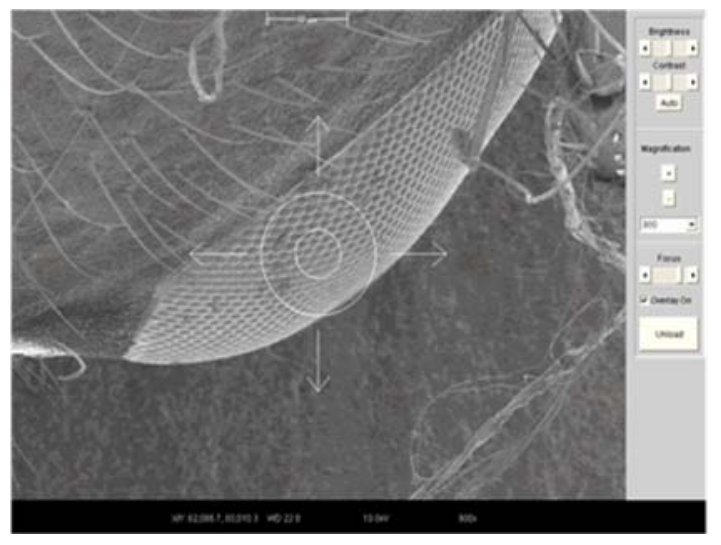

FIG. 2. A sample specimen from the NASA's Virtual Lab SEM of the eye of a fly. Materials for using this tool in middle and high school science are accessible here online: http://edcollege.ucf.edu/nasa/ 